\title{
1855 and 1991 Surveys of the San Andreas Fault: Implications for Fault Mechanics
}

\author{
by Lisa B. Grant* and Andrea Donnellan ${ }^{\dagger}$
}

\begin{abstract}
Two monuments from an 1855 cadastral survey that span the San Andreas fault in the Carrizo Plain have been right-laterally displaced $11.0 \pm$ $2.5 \mathrm{~m}$ by the 1857 Fort Tejon earthquake and associated seismicity and afterslip. This measurement confirms that at least $9.5 \pm 0.5 \mathrm{~m}$ of slip occurred along the main fault trace, as suggested by measurements of offset channels near Wallace Creek. The slip varied by 2 to $3 \mathrm{~m}$ along a $2.6-\mathrm{km}$ section of the main fault trace. Using radiocarbon dates of the penultimate large earthquake and measurements of slip from the 1857 earthquake, we calculate an apparent slip rate for the last complete earthquake cycle that is at least $25 \%$ lower than the lateHolocene slip rate on the main fault trace. Comparison of short-term broadaperture strain accumulation rates with the narrow-aperture late-Holocene slip rate indicates that the fault behaves nearly elastically over a time scale of several earthquake cycles. Therefore, slip in future earthquakes should compensate the slip-rate deficit from the 1857 earthquake.
\end{abstract}

\section{Introduction}

Models of earthquake recurrence, calculations of earthquake probability, and theories about the behavior and segmentation of strike-slip faults are often based on estimates of fault slip from measurements of offset landforms. Measurements of late-Holocene slip rate and small offset stream channels near Wallace Creek (Fig. 1) have led some to argue that the Carrizo section of the San Andreas fault has recurrence intervals of 240 to $450 \mathrm{yrs}$. These unusually long intervals result from unusually large $(9.5$ to $12.3 \mathrm{~m})$ offsets, the smallest of these $(9.5 \mathrm{~m})$ being ascribed to the latest large earthquake in 1857 (Sieh and Jahns, 1984; Sieh et al., 1989). It is difficult to prove that each offset corresponds to one earthquake, however. In fact, several channels 2 to $5 \mathrm{~km}$ southeast of Wallace Creek, which are offset only 6.5 to $7.5 \mathrm{~m}$ (Grant and Sieh, 1993), suggest that either dextral slip varied from 6.5 to $10 \mathrm{~m}$ within a few kilometers along the fault during the 1857 earthquake, or the individual offsets near Wallace Creek were actually formed by multiple earthquakes. This latter possibility could mean that the time between at least some past earthquakes was less than 240 yrs and that the maximum slip in 1857 may have been less than $9.5 \mathrm{~m}$ (Grant and Sieh, 1993).

To resolve this ambiguity and measure directly the

\footnotetext{
*Present address: Woodward-Clyde Consultants, 2020 East First Street, Suite 400, Santa Ana, California 92705.

${ }^{\dagger}$ Present address: Jet Propulsion Laboratory, California Institute of Technology, Pasadena, California 91109.
}

amount of slip from the 1857 earthquake, we recovered original monuments from an 1855 survey spanning the San Andreas fault near Wallace Creek and resurveyed them with the Global Positioning System (GPS). From these measurements and other observations we have inferred characteristics of the fault over one earthquake cycle and discuss them in relation to long-term properties of the fault.

\section{The Rectangular Survey System}

The rectangular survey system was established by the United States in 1785 to facilitate land settling in the western territories (White, 1983). Land was divided into townships 6-miles $(9655.56 \mathrm{~m})$ square by lines oriented east-west (township lines) and north-south (range lines) with corrections for magnetic declination (White, 1983). Townships were subdivided into 36 sections, each 1-mile $(1609.26 \mathrm{~m})$ square. In the mid- to late-1800s the land in the Carrizo Plain and Temblor Range was divided into townships and subdivided into sections. James E. Freeman sectioned and surveyed the land near Wallace Creek in 1855 and 1856. Freeman also surveyed township boundaries in the Temblor Range in 1855 (Fig. 2). These townships were later subdivided by other surveyors.

During the $1800 \mathrm{~s}$, surveyors used chains to measure horizontal distances. The chains were kept level and under tension during the surveys. The method of chaining has a low accuracy, but is sufficient to estimate line- 


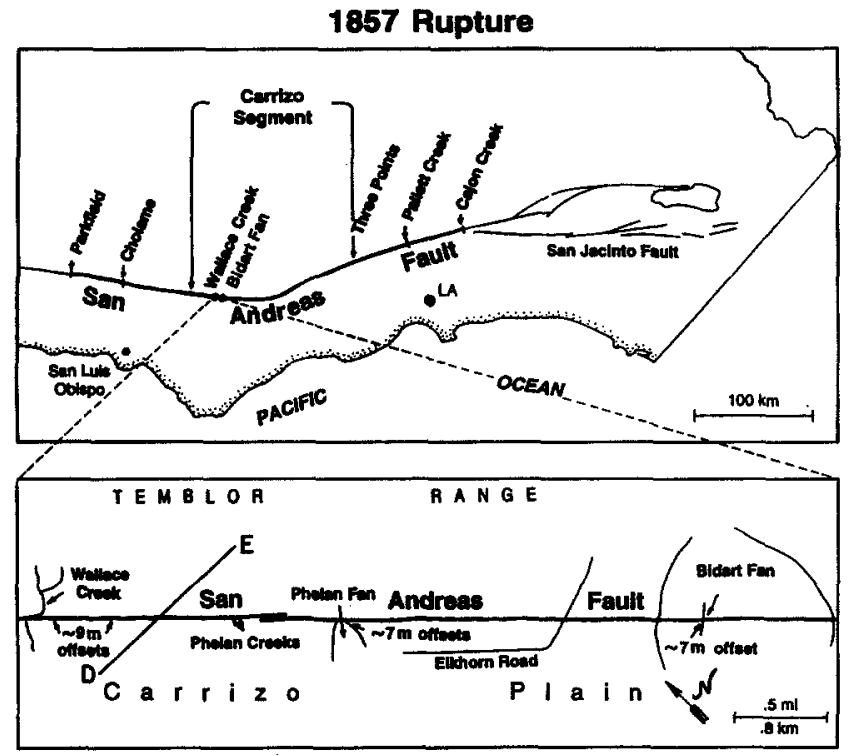

Figure 1. Location map of the San Andreas fault in southern California. Resurveys of 1855 section lines in the Carrizo Plain enable estimation of coseismic dextral displacement. The 1857 rupture is in bold (Sieh, 1978). Inset map shows Wallace Creek, measured line DE, and location of small stream channels offset 9 to $10 \mathrm{~m}$ near Wallace Creek, and $7.2 \pm 0.5 \mathrm{~m}$ at the Bidart fan (Sieh and Jahns, 1984; Grant and Sieh, 1993). Buried channels at the apex of the Phelan fan are offset 6.6 to $6.9 \mathrm{~m}$ (Grant and Sieh, 1993). Geodetic measurements suggest about $11 \mathrm{~m}$ of co-seismic offset.

length changes of a few meters for a 1-mile (1609.26 m) section line. Distances were measured by a chain $66-$ $\mathrm{ft}(20.12 \mathrm{~m})$ long with 100 links. Eighty chains make up 1 mile $(1609.26 \mathrm{~m})$. In establishing the township and range lines the distance along each section was measured twice, and the lines were remeasured when the land was subdivided (White, 1983). Six section lines were measured out consecutively. The first five lines were as close as possible to 80 chains in length. The sixth line was adjusted to intersect the township boundary, and its deviation from 80 chains was recorded (White, 1983). The surveyors used a solar compass to ensure that the lines were straight and properly oriented (White, 1983). The corners of each section were generally marked by a post in a mound of earth or stones. In some cases, stones, approximately 35 by 30 by $8 \mathrm{~cm}$, were used in lieu of posts.

\section{Survey and Error Analysis}

We searched microfiche copies of original field notes and plats (maps) of early surveys spanning the San Andreas fault in the Carrizo Plain. Then we examined recent (1950s) USGS topographic quadrangle maps of

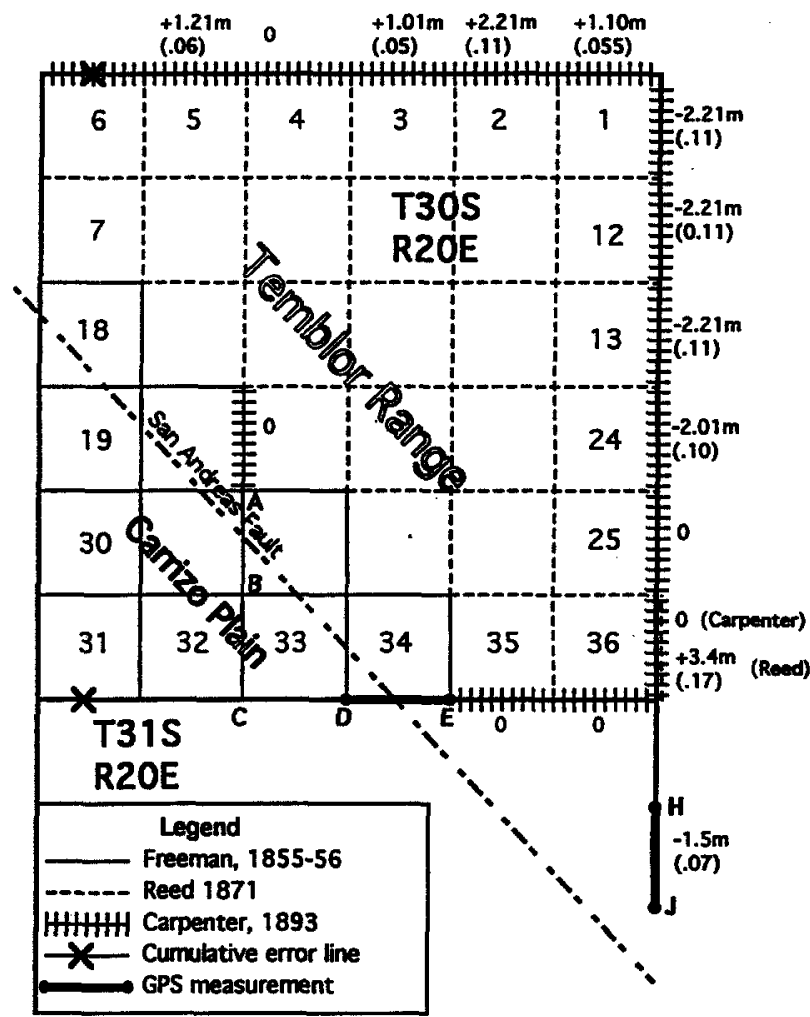

Figure 2. Map of surveyed section lines and land-survey grid of Township 30 south, Range 20 east (T30S, R20E) and part of Township 31 south, Range 20 east (T31S, R20E) referenced to the Mount Diablo Meridian and Baseline, California. Exterior sections are numbered. Each section is approximately 1-mile square. Line types indicate areas surveyed by Freeman, resurveyed by Carpenter, Reed, and by us. Differences in horizontal distance between Freeman's survey and resurveys are shown in meters and in chains (parentheses) next to the resurveyed lines. The end points of lines $\mathrm{DE}$ and $\mathrm{HJ}$ are marked with corresponding letters.

townships surveyed prior to 1857 to identify potential remaining section markers. We recovered 15 candidate section markers, and checked Freeman's field notes and plats for authenticity. We conclude that Freeman accurately recorded natural landmarks and performed the survey.

Most section markers did not match Freeman's original description and had obviously been reset since the original survey. We searched records of resurveys and remonumentation filed with the Bureau of Land Management (BLM) and the San Luis Obispo County Surveyor to find the history of each recovered marker. Because the Carrizo Plain is sparsely populated, few resurveys have been made, and several remonumentations are not on record with the county. United States Geological Survey topographic maps indicate that by the 1950s nearly all of the monuments in the Carrizo Plain had been obliterated or lost. 
We found and surveyed a total of eight potential monuments. Four of the monuments were reset by twentieth-century surveyors. One of the monuments is a replacement of a lost marker, and therefore is not in its original location. Two of the remaining three were reset without record, or the records were destroyed in a fire in San Luis Obispo, California, in 1981. Our measurements suggest that surveyors reset these monuments well outside their original locations. We eliminated from our study monuments that were reset without record, because they may have been moved from their original locations. Of the remaining four sites, two are the degraded, original monuments, and two appear to be in the locations of the original monuments (Grant, 1993). The original monuments ( $D$ and $E$ ) form a line spanning the fault. The other monuments ( $H$ and $J$ ) are on a range line that does not cross the fault. We were unable to find any other original pre-1857 monuments in the Carrizo Plain region to resurvey with GPS.

In 1991 we remeasured both lines. To minimize errors, we used GPS dual frequency receivers to remeasure horizontal distance between the monuments. GPS does not require line of sight so it was only necessary to observe at the end points. Conventional surveying techniques would have required traverses between the monuments, thus increasing measurement error. We collected data simultaneously for each of the lines measured, for a period of 1 to $3 \mathrm{hr}$. By simultaneously sampling data we eliminate the possibility of errors resulting from adjustment of a network. We used precise orbits obtained from Scripps Institution of Oceanography to process the data. Results are shown in Table 1. Formal errors in the GPS survey are 1 to $4 \mathrm{~cm}$, which is representative of the true $1 \sigma$ errors.

Errors in the original survey are much larger than the GPS errors. In the following discussion we mix units of meters and miles $(1609.26 \mathrm{~m})$ because the original survey was measured in miles and we are measuring deviations from 1 mile. The total measurement error is dominated by line-length errors in the original chained survey and errors in recognizing the center of degraded original monuments. Since we only remeasured distances between consecutive section corners, azimuth errors are not of concern. Historical resurveys of Freeman's 1855 survey (Fig. 2) of T30S and R20E indicate that Freeman's average chaining error was less than 1:950 for a 1-mile line. One interior section line established in 1856 was remeasured by John Reed in 1871 , and 14 additional lines in the Temblor Range were remeasured by Howard Carpenter in 1893. Although we are unable to establish the absolute accuracy of the method of chaining, we can use the repeated line measurements to estimate the precision of the method.

Comparison of the repeat measurements with the originals, including our measurement of distance $\mathrm{HJ}$, yields a root-mean-square (rms) error of $1.6 \mathrm{~m}$ for a 1-mile $(1609.26 \mathrm{~m})$ section line. All of the repeated measurements except line $\mathrm{HJ}$ were conducted in mountainous terrain. The largest deviation from 1 mile $(3.4 \mathrm{~m})$ is probably larger than Freeman's error because it was measured along a "random" line. [A random line was laid out before the true line was measured. To prevent confusion between true and random lines the surveyors were required to work around vegetation and trees rather than blaze them, thus making random lines less accurate (White, 1983).] The largest deviation measured by Carpenter in "mountainous" terrain was $2.2 \mathrm{~m}$. The terrain across line DE is flat to rolling, so we assume that the average error of $1.6 \mathrm{~m}(1 \sigma)$ applies to our measurement line across the San Andreas.

There is additional uncertainty in determining the center of the monuments. For monuments D, H, and $J$, the uncertainty is less than half a meter. Site $\mathrm{E}$ is marked by a diffuse mound of stones approximately $0.6 \mathrm{~m}$ in radius. Uncertainty in surveying to the same position as Freeman increases the overall line-length error to $1.7 \mathrm{~m}$. The San Andreas strikes 48 degrees from measurement line $\mathrm{DE}$, so the fault parallel error is $2.5 \mathrm{~m}(1 \sigma)$.

\section{Results}

The length change of line DE corresponds to 11.1 $m$ of dextral displacement parallel to the fault, if one does a simple trigonometric correction assuming purely dextral slip between two blocks. Assuming a constant strain rate since the 1857 earthquake, and using velocities estimated from recent surveys (Lisowski et al., 1991), we calculate that line-length $\mathrm{DE}$ has increased $0.1 \mathrm{~m}$ as a result of post-seismic strain accumulation since the 1857 earthquake. This amount of post-seismic displacement is small compared to the errors associated with the survey. Time-dependent effects such as viscoelastic relaxation

Table 1

Line Lengths, Formal Errors, Total Displacement, Post-Seismic Accumulation, and Fault Parallel Displacement

\begin{tabular}{ccccccc}
\hline Line & $\begin{array}{c}\text { Horizontal } \\
\text { Distance }(\mathrm{m})\end{array}$ & $\begin{array}{c}\Delta \text { Mile } \\
(1609.265 \mathrm{~m})\end{array}$ & $\begin{array}{c}\text { Formal } \\
\text { Error }(\mathrm{m})\end{array}$ & $\begin{array}{c}\text { Fault Slip } \\
\text { (Right-Lateral) }\end{array}$ & $\begin{array}{c}\text { Post-Seismic } \\
\text { Accumulation }\end{array}$ & $\begin{array}{c}\text { Fault Parallel } \\
\text { Displacement }\end{array}$ \\
\hline DE & 1616.713 & +7.448 & 0.009 & $11.1 \mathrm{~m}$ & $0.1 \mathrm{~m}$ & $11.0 \mathrm{~m}$ \\
HJ & 1608.064 & -1.201 & 0.040 & N/A & N/A & N/A \\
\hline
\end{tabular}


following the earthquake are negligible over such a short distance from the fault. Subtracting $0.1 \mathrm{~m}$ of post-seismic deformation, we calculate that markers $\mathrm{D}$ and $\mathrm{E}$ were displaced $11.0 \pm 2.5 \mathrm{~m}(1 \sigma)$ relative to each other by the 1857 earthquake and associated foreshocks, aftershocks, and afterslip.

\section{Discussion}

There are two important conclusions from the preceding result. First, since there have been no large earthquakes on the San Andreas fault in the Carrizo Plain since 1857 (Wood, 1955) and the monuments were displaced $11.0 \pm 2.5 \mathrm{~m}$, it appears that the $9.5 \pm 0.5-\mathrm{m}$ offsets at Wallace Creek were formed by the 1857 earthquake and associated seismicity and afterslip. To the best of our knowledge, this is the largest amount of documented fault slip from any historic earthquake in the contiguous United States. To first order, the large amount of slip is consistent with the amount of accumulated strain expected to be released after the 350- to 450 -yr interval between 1857 and the penultimate large earthquake in A.D. 1405- to 1510 (Grant and Sieh, 1994; Grant, 1993).

Second, the slip along the main trace of the San Andreas apparently varied from 6.6 to $6.9 \mathrm{~m}$ at Phelan fan (Grant and Sieh, 1993) to $9.5 \pm 0.5 \mathrm{~m}$ at Wallace Creek (Sieh and Jahns, 1984), $2.6 \mathrm{~km}$ away. The magnitude of variation in slip is similar to that reported during the 1992 Landers earthquake in southern California (Rubin and McGill, 1992). This has several implications for the interpretation of geomorphic offsets. Geologists frequently use measurements of geomorphic offsets to estimate the dates and magnitudes of prehistoric earthquakes (Sieh and Jahns, 1984; Working Group on California Earthquake Probabilities, 1988; Lienkaemper and Sturm, 1989; McGill and Sieh, 1991). When interpreting geomorphic offset measurements, geologists commonly assume that the smallest offset in a given area resulted from slip in the previous earthquake. Larger offsets are then interpreted as the result of more than one earthquake, especially if the larger offset is a multiple of a smaller offset measurement. Therefore, several meters variation in slip over a few kilometers distance during past large earthquakes could lead to misinterpretation of the dates or sizes of prehistoric events. Near Wallace Creek, the 2- to 3-m difference in slip during the 1857 earthquake has led to substantial differences in estimated dates of the penultimate earthquake (Sieh et al., 1989; Grant and Sieh, 1993). Uncertainties in the interpretation of geomorphic offsets suggest that radiocarbon dating of previous earthquakes is preferable to dates estimated from analysis of geomorphic offsets.

Given that the geomorphic offsets at Wallace Creek were produced by one earthquake, we can use them to estimate the average slip rate at the fault over one earthquake cycle. The most recent large earthquake prior to
1857 occurred in A.D. 1405 to 1510 (Grant, 1993; Grant and Sieh, 1994). Thus, the time span of the last complete earthquake cycle is $400 \pm 53 \mathrm{yr}(2 \sigma)$, and the average slip rate during the last cycle at Wallace Creek was $24 \pm 4 \mathrm{~mm} / \mathrm{yr}$. At the Phelan and Bidart fans (Fig. 1) the average slip rate over the cycle is only $16 \pm 2$ and $18 \pm 3 \mathrm{~mm} / \mathrm{yr}$, respectively. (All slip-rate errors reported here are $2 \sigma$ to be consistent with the reported error bars on the date of the penultimate earthquake). These rates are lower than the late-Holocene average slip rate of $33 \pm 3 \mathrm{~mm} / \mathrm{yr}$ (recalculated from Sieh and Jahns, 1984 ) at Wallace Creek by about 25 to $50 \%$. Stated differently, if we assume elastic strain accumulated at the late-Holocene slip rate, then $13 \pm 2 \mathrm{~m}$ of slip should have accumulated during the last earthquake cycle, yet $<10 \mathrm{~m}$ of slip were released along the fault trace between Wallace Creek and the Phelan fan. Therefore, either a slip deficit resulted from the 1857 earthquake, or the slip rate of the fault is lower than far-field deformation rates or Holocene slip rates.

Despite the apparent discrepancy between pre- 1857 strain accumulation and release in 1857, we do not believe that the current rate of elastic strain accumulation differs from the late-Holocene slip rate. Geodetically determined accumulation rates from networks spanning several tens of kilometers across the Carrizo Plain (Lisowski et al., 1991; Feigl et al., 1993) are indistinguishable from millennial slip rates measured geologically across the $\sim 20$-m-wide main fault zone at Wallace Creek (Sieh and Jahns, 1984). Dislocation models that fit trilateration data and recent GPS results indicate that 31 to $35 \mathrm{~mm} / \mathrm{yr}$ of accumulation is occurring over a $175-\mathrm{km}$ wide zone spanning the fault. These rates are similar to the $32 \pm 2 \mathrm{~mm} / \mathrm{yr}$ rates of fault slip measured across the creeping section of the San Andreas fault (Lisowski and Prescott, 1981) and the late-Holocene rate at Wallace Creek. Since these measurements span short and long measurement apertures, and short ( $\leqq 10 \mathrm{yr}$ ) and long ( $\geqq 3000 \mathrm{yr}$ ) time spans, the slip rate of the fault at Wallace Creek is equivalent to the far-field strain accumulation rate, and is invariant when averaged over several earthquake cycles. Thus, despite the large amount of surface slip that accompanied the 1857 earthquake in the northern Carrizo Plain, the amount of slip appears deficient when averaged over the time since the penultimate earthquake.

All of the prior arguments are based on the assumption of elastic behavior. Permanent anelastic deformation along the fault could explain the possible discrepancy between the displacement of $D$ and $E$ and the lower geomorphic offset measurements along the fault trace. The slip-rate data, however, indicate that the deformation is almost entirely elastic when averaged over several seismic cycles, as described previously. This is consistent with the results of theoretical and laboratory models of strike-slip faulting that show that the slip varies from 
cycle to cycle but the long-term rate is constant (Rundle, 1989; King, 1991).

There may be a small amount of anelastic deformation along the section of the San Andreas fault between Wallace Creek and the Bidart fan. Several linear ridges and small scarps subparallel to the fault are probably active folds and thrusts. These structures may accommodate some co-seismic deformation. However, since the broad-aperture strain accumulation rate is the same as the $\sim 20$-m aperture fault slip rate at Wallace Creek, the component of anelastic deformation attributable to movement on secondary structures must be within the measurement error of the late-Holocene slip rate; on the order of 1 to $3 \mathrm{~mm} / \mathrm{yr}$ when averaged over several earthquake cycles. The elastic behavior of the fault suggests that either the 1857 slip deficit resulted from dynamic slip "overshoot" during the penultimate earthquake, or the surface slip in future large earthquakes should compensate the deficit.

There are several implications of the surface slip variation and apparent 1857 slip deficit for earthquake forecasting and fault mechanics. If the surficial slip during an earthquake is only roughly equivalent to the amount of strain accumulated since the last earthquake, then the size of past or future events and the "characteristic" properties of fault segments are difficult to estimate accurately from geomorphic offsets. Even if the date of an earthquake could be predicted, elastic strain accumulation models may overestimate or underestimate the amount of slip at the surface trace of a fault during the earthquake by up to $25 \%$ or more. In the design of critical structures that cross active faults, it would be prudent to anticipate greater amounts of co-seismic slip than the amount estimated from long-term elastic strain accumulation models.

\section{Acknowledgments}

The research described in this article was carried out at the Seismological Laboratory and Jet Propulsion Laboratory of the California Institute of Technology, and at NASA Goddard Space Flight Center, under contract with the USGS (grant \#14-08-001-G-1789 awarded to Kerry Sieh), the Caltech Earthquake Research Affiliates, NASA, and fellowships from the National Research Council and F. Beach Leighton. Larry Vredenburgh of BLM, Bakersfield, brought the early surveys to our attention. We thank Kerry Sieh and Hiroo Kanamori for their support. Steve Bryant assisted in the field. Leonard Bidart granted access to his property. We thank Paul Dunham, Jay Satalich and others at Caltrans for the loan of GPS equipment. We appreciate the contributions of D. Manion, M. McGee, C. B. Worden, S. Grant, E. Grant, and several reviewers. Caltech Division of Geological and Planetary Sciences contribution \#5249.

\section{References}

Grant, L. B. and K. Sieh (1993). Stratigraphic evidence for seven meters of dextral slip on the San Andreas fault during the 1857 earthquake in the Carrizo Plain, Bull. Seism. Soc. Am. 83, 619635.

Grant, L. B. and K. Sieh (1994). Paleoseismic evidence of clustered earthquakes on the San Andreas fault in the Carrizo Plain, California. J. Geophys. Res. (in press).

Grant, L. B. (1993). Characterization of large earthquakes on the San Andreas fault in the Carrizo Plain: implications for fault mechanics and seismic hazard, Ph.D. Thesis, California Institute of Technology, Pasadena.

Feigl, K. L., D. C. Agnew, Y. Bock, D. Dong, A. Donnellan, B. H. Hager, T. A. Herring, D. D. Jackson, T. H. Jordan, R. W. King, S. Larsen, K. M. Larson, M. H. Murray, Z. Sheng, and F. H. Webb (1993). Measurement of the velocity field of central and southern California, 1984-1992, J. Geophys. Res. 98, 2167721712.

King, C.-Y. (1991). Multicycle slip distribution along a laboratory fault, J. Geophys. Res. 96, 14377-14381.

Lisowski, M., J. C. Savage, and W. H. Prescott (1991). The velocity field along the San Andreas fault in central and southern California, J. Geophys. Res. 96, 8369-8389.

Lisowski, M. and W. H. Prescott (1981). Short-range distance measurements along the San Andreas fault system in Central California, 1975-1979, Bull. Seism. Soc. Am. 71, 1607-1624.

Lienkaemper, J. J. and T. A. Sturm (1989). Reconstruction of a channel offset in 1857 by the San Andreas fault near Cholame, California, Bull. Seism. Soc. Am. 79, 901-909.

McGill, S. F. and K. E. Sieh (1991). Surficial offsets on the central and eastern Garlock fault associated with prehistoric earthquakes, J. Geophys. Res. 96, 21597-21621.

Okada, Y. (1985). Surface deformation due to shear and tensile faults in a half-space, Bull. Seism. Soc. Am. 75, 1135-1154.

Rubin, C. R. and S. F. McGill (1992). The June 28, 1992 Landers earthquake: slip distribution and variability along a portion of the Emerson fault, EOS 73, no. 43, 362.

Rundle, J. B. (1989). A physical model for earthquakes 2. Application to Southern California, J. Geophys. Res. 93, 6255.

Sieh, K. E., M. Stuiver, and D. Brillinger (1989). A more precise chronology of earthquakes produced by the San Andreas fault in Southern California, J. Geophys. Res. 94, 603-623.

Sieh, K. E. and R. H. Jahns (1984). Holocene activity of the San Andreas fault at Wallace Creek, California, Geol. Soc. Am. Bull. 95, 883-896.

Sieh, K. E. (1978). Slip along the San Andreas fault associated with the great 1857 earthquake, Bull. Seism. Soc. Am. 68, 1421-1448.

White, C. A. (1983). A History of the Rectangular Survey System, Bureau of Land Management, U.S. Dept. of Interior, U.S. Government Printing Office, Washington, D.C.

Wood, H. O. (1955). The 1857 earthquake in California, Bull. Seism. Soc. Am. 45, 47-67.

Working Group on California Earthquake Probabilities (1988). Probabilities of large earthquakes occurring in California on the San Andreas fault, U.S. Geo. Surv. Open-File Rep. 88-398.

\section{Appendix}

It is interesting to estimate how deeply the slip deficit may have extended. We can do so by reconciling the observed measurements. Assuming isotropic homogeneous elastic properties, we have calculated the predicted displacement of marks $\mathrm{D}$ and $\mathrm{E}$ for different faultslip distributions (after Okada, 1985). In the absence of subsurface geologic data, we chose a simple two-part fault-slip model in which constant slip occurs in the lower part and horizontally varying but vertically constant slip 


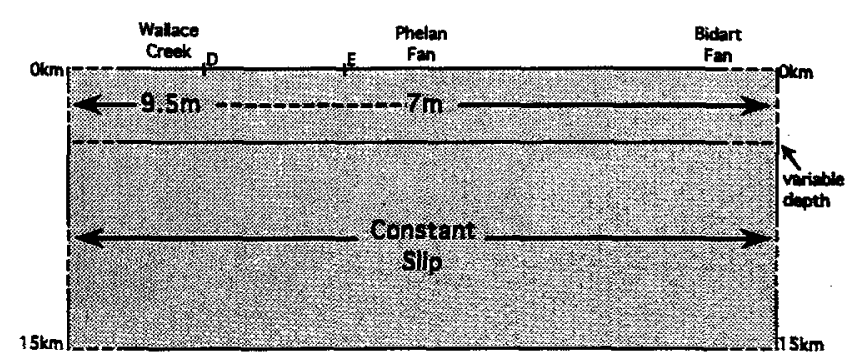

Figure A1. Dimensions of the two-part model used in the elastic dislocation model. The figure shows a section along the San Andreas fault with the locations of monuments $\mathrm{D}$ and $\mathrm{E}$ projected onto the fault. Vertically constant right-lateral displacement is imposed on each part. Displacement of the upper part varies horizontally with $9.5 \mathrm{~m}$ of slip imposed from Wallace Creek northward, 7 $m$ of slip imposed from the Phelan fan southward, and a linear interpolation of slip between Wallace Creek and Phelan fan.

occurs in the upper part with the specified slip matching the observed slip at Wallace Creek and the Phelan and Bidart fans (Fig. A1). Note that this is a quasi-one-dimensional model since we do not specify the two-dimensional details of slip in either the upper or lower part. We varied the depth of the boundary between the upper and lower parts, and also the amount of slip at depth. The lower part extends $15 \mathrm{~km}$ to the base of the seismogenic zone. The results indicate that the upper part of variable slip is thin and probably does not extend much deeper than about 1 or $2 \mathrm{~km}$, because there is a steep gradient in the curve at 1 to $2 \mathrm{~km}$ (Fig. A2). If the true offset of marks D and $E$ matches that measured at Wallace Creek, then the upper part could be even thicker. This would result in a deeper slip deficit with possibly

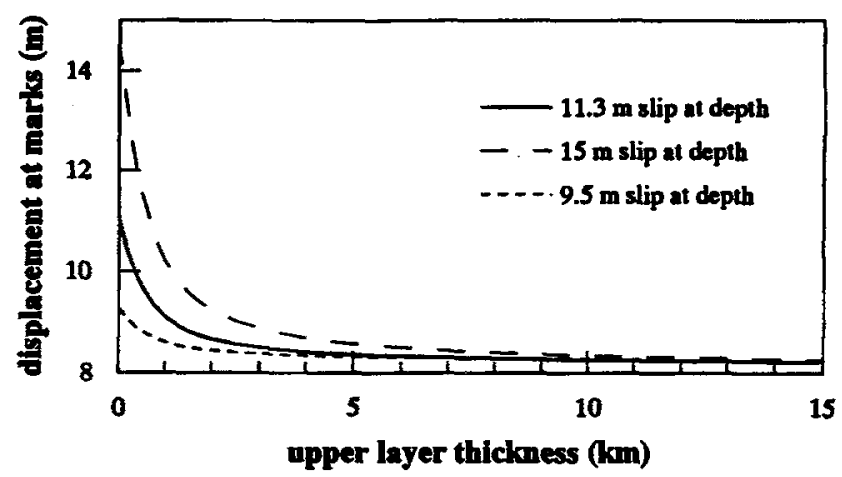

Figure A2. Displacement of monuments D and $E$ calculated from the elastic dislocation model for varying thicknesses of the upper part, and slip of $9.5,11.3$, or $15 \mathrm{~m}$ on the fault in the lower part. Properties of the lower part are constant horizontally and vertically to a depth of $15 \mathrm{~km}$. Results suggest that the upper, variable-slip part of the fault is at least $1-\mathrm{km}$ thick.

more than $11 \mathrm{~m}$ of slip at depth. If the behavior is elastic, the surface slip during the 1857 earthquake, as represented by geomorphic offsets, may not reflect the total average slip on the fault at depth, particularly if the true offset of $\mathrm{D}$ and $\mathrm{E}$ is at the upper bound of the error.

Seismological Lab 252-21

California Institute of Technology

Pasadena, California 91125

(L. B. G.)

NASA Goddard Space Flight Center

Greenbelt, Maryland 20771

(A. D.)

Manuscript received 6 July 1993. 